\title{
Systolic blood pressure, not BIS, is associated with movement during laryngoscopy and intubation
}

\author{
[Contrairement au niveau du BIS, le niveau de pression artérielle systolique est \\ associé aux mouvements lors de la laryngoscopie et l'intubation]
}

Velislav Slavov MD, Cyrus Motamed MD, Nicole Massou MD, Yves Rebufat MD, Philippe Duvaldestin MD

Objective: To compare bispectral index (BIS) values to hemodynamic variations, in order to evaluate adequacy of anesthesia during orotracheal intubation with muscle relaxants.

Methods: Forty-one patients ASA I-II, scheduled for elective peripheral surgery under general anesthesia with tracheal intubation were enrolled in the study. Fentanyl/thiopental followed by vecuronium were used for induction. Onset of relaxation was monitored at the orbicularis occuli $(\mathrm{O})$ muscle using train-of-four stimulation. Intubation was performed when no response at the $\bigcirc$ was detected visually. Intubating conditions were noted. The "isolated forearm" technique was used to detect movement during laryngoscopy/intubation. BIS values, pulse rate (PR), and systolic pressure were recorded before induction, during laryngoscopy/intubation and $60 \mathrm{sec}$ after intubation.

Results: Although intubating conditions were clinically adequate for all patients, ten out of $4 \mathrm{I}$ had movement of the isolated arm during laryngoscopy/intubation. BIS values were not significantly different for these patients: 67 (55-83) compared to those who had no movement: 60 (35-80), $P=0.6$. During laryngoscopy, PR increased for all patients while systolic pressure increased significantly only in patients who moved: $125(100-136) \mathrm{mmHg}$ vs those who did not: 108 (67-|40), $P<0.05$.

Conclusion: Systolic pressure elevations were associated with inadequate anesthesia as evaluated by the "isolated forearm" technique, during laryngoscopy/intubation. BIS values were not different between groups, suggesting that systolic blood pressure may be a better predictor of inadequate anesthesia under the circumstances described.

Objectif: Évaluer l'analyse bispectrale (BIS) en la comparant avec les variations hémodynamiques lors de l'intubation orotrachéale avec curarisation.
Méthode : Quarante et un patients de classe ASA I-II admis pour une intervention chirurgicale périphérique programmée sous anesthésie générale avec intubation et curarisation ont été inclus dans l'étude. L'induction a été effectuée avec du fentanyl/thiopental suivi de vécuronium pour faciliter l'intubation. L'installation du bloc neuromusculaire a été contrôlée à l'orbiculaire de l'œil avec des stimulations en trainde-quatre. L'intubation a été réalisée à la disparition de la réponse observée de l'orbiculaire de l'œil et les conditions d'intubation ont été notées. La technique de l'avant-bras isolé avec un garrot a été utilisée pour détecter les mouvements lors des stimuli nociceptifs alors que les patients étaient curarisés. Les valeurs du BIS, la fréquence cardiaque, et la pression artérielle systolique ont été enregistrées : avant l'induction, lors de la laryngoscopie/intubation et 60 sec après l'intubation.

Résultats : Les conditions d'intubation étaient cliniquement satisfaisantes pour tous les patients. Dix patients sur 4 I ont eu des mouvements de l'avant-bras durant la laryngoscopie et/ou l'intubation. Les valeurs du BIS chez ces patients : 67 (55-83) n'étaient pas significativement différentes de celles des patients n'ayant pas bougé : 61 (39-80) $P=0,6$. La fréquence cardiaque a augmenté chez tous les patients tandis que la pression artérielle systolique était significativement plus basse chez les patients qui n'ont pas bougé : 108 (67-140) $\mathrm{mmHg}$ contre : 125 (100-136), $(P<0,05)$

Conclusion : Dans les conditions de cette étude, les variations de la pression artérielle systolique ont été plus significatives que les variations du BIS pour prédire les mouvements du bras isolé lors de l'intubation chez les patients curarisés.

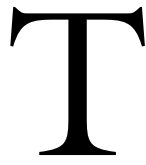

HE bispectral index (BIS) is a variable derived from the electroencephalograph (EEG) and has the ability to quantify the hypnotic component of the anesthetic state. ${ }^{1-3}$ The method is based on a computed mathematical analysis of the power spectrum synchroniza-

Du service d'anesthésie-réanimation Hôpital Henri-Mondor, AP-HP et Université Paris XII, Créteil, France.

Address correspondence to: Dr. C. Motamed, Service d'anesthésie-réanimation, Hôpital Henri Mondor-AP-HP et Université Paris XII,

51 Ave. Maréchal De Lattre de Tassigny, 94010 Créteil, France. Phone: 01-49-81-2383; Fax: 01-49-81-2380;

E-mail: cyrus.motamed@hmn.ap-hop-paris.fr

Accepted for publication February 11, 2002.

Revision accepted August 14, 2002. 
tion of the EEG. ${ }^{4}$ In conscious subjects the BIS value approximates 100. For most anesthetic agents, the BIS values decrease with the depth of anesthesia. ${ }^{4}$ It is commonly admitted that BIS values of $40-60$ correlate well with adequate hypnosis. ${ }^{4-7}$ However, adequate general anesthesia requires at least three components: hypnosis (unconsciousness), analgesia and immobility. Classically, movements in response to noxious stimulation are used to describe and to compare the potency of anesthetic agents but, in fact, they are signs of an inadequate depth of anesthesia. The use of muscle relaxants abolishes the motor response to inadequate anesthesia and, thereby, might contribute to inadvertent awareness. ${ }^{3,8,9}$ The "isolated forearm" technique described in 1977 by Tunstall is an acceptable method to detect movement in patients receiving muscle relaxants. ${ }^{10}$ False positives and negatives are possible with this technique ${ }^{4,8,9}$ but it remains a simple and noninvasive method. Nevertheless, the technique is limited in duration because of the application of an arterial tourniquet.

The present study was designed to compare BIS values and hemodynamic changes in order to evaluate adequacy of anesthesia during induction and tracheal intubation facilitated by the administration of muscle relaxants. The "isolated forearm" technique was used to detect movement in response to noxious stimuli such as laryngoscopy and intubation.

\section{Methods}

After Ethic's Committee approval and informed consent 41 adult patients, class ASA I or II scheduled for peripheral surgery under general anesthesia with tracheal intubation were enrolled. Patients with cerebral pathology, altered conscience, history of hypertension, epilepsy or muscle disorders were not included. An Aspect A-1000 EEG monitor (Aspect Medical Systems, Natick, MA, USA) was used for BIS recording. Commercially available silver-silver chloride EEG pads (Zipprep; Aspect Medical Systems) were attached to the subject's forehead according to a standard montage. One was the ground (Fpz), and the other two were placed over the left and right prefrontal cortex (F7-F8) giving a bifrontal bipolar signal. Electrode impedance was kept less than $2 \mathrm{k} \Omega$. BIS values were recorded before induction, immediately before laryngoscopy and $60 \mathrm{sec}$ after tracheal intubation.

All patients received $1.5 \mathrm{mg} \cdot \mathrm{kg}^{-1}$ of hydroxyzine as premedicant approximately one hour before anesthesia. General anesthesia was induced with $2 \mu \mathrm{g} \cdot \mathrm{kg}^{-1} \mathrm{fen}$ tanyl as a bolus, followed by thiopental $\left(4-5 \mathrm{mg} \cdot \mathrm{kg}^{-1}\right)$ titrated with additional boluses of $50 \mathrm{mg}$ to produce corneal reflex abolition and apnea. Once manual ven- tilation via face mask $\left(\mathrm{O}_{2}, 100 \%\right)$ was established, vecuronium $0.1 \mathrm{mg} \cdot \mathrm{kg}^{-1}$ was injected in five seconds.

The onset of the neuromuscular blocking effect of vecuronium was monitored by visual estimation of the responses of the orbicularis occuli muscle $(\mathrm{OO})$ elicited by supramaximal train-of-four stimulations $(30 \mathrm{~mA}$ every $12 \mathrm{sec}$ ) of the facial nerve. Mask ventilation $\left(\mathrm{F}_{\mathrm{I}} \mathrm{O}_{2}=100 \%\right)$ was maintained to control expired $\mathrm{CO}_{2}$ (29-40 $\mathrm{mmHg}$ ) until maximal depression of responses at the OO was observed. Laryngoscopy and intubation were then performed using the same laryngoscope and blade (Macintosh \#3) ${ }^{11}$ and the same investigator (V.S.). Intubating conditions were evaluated according to good clinical research practice $(\mathrm{GCRP})^{12}$ recommendations as: $1=$ excellent, $2=$ good, 3 = difficult.

A pneumatic tourniquet was installed on the forearm opposite to the infusion. The "isolated forearm" was not immobilized and was installed in prone position, abducted at $90^{\circ}$ on a soft support. The tourniquet was inflated at a pressure of $50 \mathrm{mmHg}$ above the systolic blood pressure (SBP) just before the injection of the vecuronium.

An investigator unaware of BIS values observed movements of the isolated arm. Noninvasive measure of SBP and pulse rate (PR) (Dynamap ${ }^{\circledR}$, Critikon, USA) were recorded every $60 \mathrm{sec}$, before and during laryngoscopy/intubation, and $60 \mathrm{sec}$ after tracheal intubation. The day after surgery, patients were questioned in order to detect any recall of per anesthetic awareness.

For statistical analysis, Mann-Withney and Wilcoxon tests were used to compare independent and paired data respectively. Values are presented as median and extreme values (minimum-maximum). A $P<0.05$ value was considered significant. To detect a relation between SBP, BIS and movement, a logistic regression analysis was performed using SPSS for Windows R 10 (SPSS Inc., USA). The sample size was chosen on the basis of a similar study comparing BIS and another method (EEG) for prediction of the hemodynamic response to laryngoscopy and tracheal intubation. ${ }^{13}$

\section{Results}

All patients had a BIS value greater than 97 before induction (Table). Intubating conditions were rated excellent or good $(1 / 2)$ for all patients. The median onset time of neuromuscular blockade was $195 \mathrm{sec}$ (range: 150-260).

Time from laryngoscopy to intubation was less than one minute for all patients.

Ten patients moved their "isolated forearm" $(\mathrm{MVT}+)$ during laryngoscopy/intubation $(24 \%)$. The 
TABLE Demographic variables and principal findings according to presence or absence of movement during laryngoscopy

\begin{tabular}{|c|c|c|c|}
\hline & $M V T-(n=31)$ & $M V T+(n=10)$ & Significance \\
\hline $\operatorname{Sex}(M / F)$ & $20 / 11$ & $7 / 3$ & NS \\
\hline Age (yr) & $51(28-70)$ & $45(35-69)$ & NS \\
\hline Weight (kg) & $72(52-97)$ & $73(63-90)$ & NS \\
\hline Fentanyl ( $\mu \mathrm{g})$ & $150(125-175)$ & $150(125-175)$ & NS \\
\hline Thiopental (mg) & $350(275-600)$ & $375(300-650)$ & NS \\
\hline Onset OO $(\mathrm{sec})$ & $200(160-260)$ & $185(150-220)$ & NS \\
\hline Intubating conditions (I/II/III) & $(13 / 18 / 0)$ & $(3 / 7 / 0)$ & NS \\
\hline Pulse rate at induction & $73(62-92)$ & $70(60-90)$ & NS \\
\hline Pulse rate during laryngoscopy/intubation & $76(64-99)$ & $70(53-101)$ & NS \\
\hline Pulse rate $60 \mathrm{sec}$ after intubation & $86(59-128)$ & $81(52-120)$ & NS \\
\hline SBP at induction & $135(95-150)$ & $138(99-160)$ & NS \\
\hline SBP at laryngoscopy/intubation & $108(67-140)$ & $125(100-136)$ & $P<0.05$ \\
\hline SBP $60 \mathrm{sec}$ after intubation & $160(101-180)$ & $164(132-190)$ & NS \\
\hline BIS at induction & $98(96-100)$ & $98(97-99)$ & NS \\
\hline BIS during laryngoscopy/intubation & $60(39-80)$ & $67(55-83)$ & NS \\
\hline BIS $60 \mathrm{sec}$ after intubation & $72(59-88)$ & $77(71-87)$ & NS \\
\hline
\end{tabular}

Values are expressed as median (range). $\mathrm{OO}=$ orbicularis occuli; $\mathrm{SBP}=$ systolic blood pressure; BIS $=$ bispectral index; NS $=$ not significant

BIS values for these patients, 67 (55-83), were not significantly different from values of patients who did not move (MVT-), 60 (39-80). Onset time of maximum neuromuscular blockade was not different between MVT+ and MVT-. SBP values before laryngoscopy were lower $108(67-140) \mathrm{mmHg}$ in the MVT- than in the MVT+ group, $125(100-136)$ $\mathrm{mmHg},(P<0.05)$. This difference in SBP was not observed after intubation: $160(101-180) \mathrm{mmHg}$ in MVT-ps 164 (132-190) mmHg in MVT+ group (NS). PR variations during laryngoscopy/intubation were not significantly different between MVT+ and MVT- (TABLE). The SBP variation contributed significantly to the prediction of movement (Chi square statistics $=26, P<0.01$, odds ratio $=1.2$ ), while BIS variation did not fit the model adequately (Chi square statistics $=3, P=0.06$ ).

Repetitive stimulations due to monitoring of neuromuscular blockade at the facial nerve yielded some artifacts in the BIS monitor without affecting BIS values.

The day after surgery no patient recalled awareness during anesthesia.

\section{Discussion}

This study shows that the "isolated forearm" technique detected movement in $24 \%$ of patients during laryngoscopy and intubation. Hemodynamic variations at the end of induction, prior to intubation, were significantly different between patients who moved and those who did not. Although BIS values tended to be lower in MVT- their variation was not a significant predictor of movement.
Several investigations have been conducted to evaluate the value of BIS to predict movement during anesthesia, $, 3,13,14$ however, the relationship between intubating conditions and BIS remains unclear. Indeed, laryngoscopy and intubation are important stimuli and are associated with more intense catecholamine release than surgical incision. ${ }^{15}$

Acceptable intubating conditions, as argued in GCRP, ${ }^{12}$ are obviously an appropriate "end point" and represent the goal of an adequate anesthetic induction. In the present study no significant difference was observed in intubating conditions between groups. However, the sample size was not calculated to address this issue. In a recent study, Guignard et al. ${ }^{16}$ assessed reactivity to laryngoscopy and intubation at different remifentanil target concentration during a constant infusion of propofol. Remifentanil did not produce any modification of BIS values even at the highest target concentration but influenced the hemodynamic profile. ${ }^{16}$ In addition, a strong correlation between movement during intubation and target remifentanil concentration was noted but the correlation between hemodynamic changes and movement was not evaluated. In our study, a positive correlation between hemodynamic changes and movements was established. Thus, our findings confirm those of Guignard et al. ${ }^{16}$ on the lack of association between BIS and movement in response to noxious stimuli.

In many patients BIS values remained high (above $60)$ prior to laryngoscopy, a finding that could suggest an insufficient anesthetic depth for these patients. Nevertheless, titration of the hypnotic to clinical "end 
points" such as abolition of the ciliary reflex is still a widely accepted standard. However, this practice might be reconsidered in view of our results. Nevertheless, no patients experienced awareness during induction.

Theoretically, BIS values could have been influenced by the repetitive stimulations of $\mathrm{OO}$ as the BIS signal might have been "contaminated" by the electromyographic activity of facial muscles. However, it has been reported that BIS elevation due to this activity disappears when paralysis occurs. ${ }^{17}$

In summary, this study suggests that SBP changes after induction of anesthesia could be more sensitive than BIS values in predicting movement in response to laryngoscopy/intubation.

\section{References}

1 Lin J, Singh H, White PF. Electroencephalographic bispectral index correlates with intraoperative recall and depth of propofol-induced sedation. Anesth Analg 1997; 84: 185-9.

2 Vernon JM, Lang E, Sebel PS, Manberg P. Prediction of movement using bispectral electroencephalographic analysis during propofol/alfentanil or isoflurane/alfentanil anesthesia. Anesth Analg 1995; 80: 780-5.

3 Kearse LA Jr, Manberg P, Chamoun N, deBros F, Zaslavsky A. Bispectral analysis of the electroencephalogram correlates with patient movement to skin incision during propofol/nitrous oxide anesthesia. Anesthesiology 1994; 81: 1365-70.

4 Billard $V$. Surveillance de la profondeur de l'anesthésie. In: Conférences d'Actualisation. 1997 Elsevier, Paris, et SFAR, 1997: 17-32.

5 Sleigh JW, Andrzejowski J, Steyn-Ross A, Steyn-Ross M. The bispectral index: a measure of depth of sleep? Anesth Analg 1999; 88: 659-61.

6 Drummond JC. Monitoring depth of anesthesia. With emphasis on the application of the bispectral index and the middle latency evoked response to the preventionof recall. Anesthesiology 2000; 93: 876-82.

7 Mollestad KE, Heier T, Steen PA, Raeder JC. I MACincision sevoflurane prevents explicit awareness during surgical skin incision and tracheal intubation. Acta Anaesthesiol Scand 1998; 42: 1184-7.

8 Schwender D, Daunderer M, Kunze-Kronawitter H, Klasing S, Poppel E, Peter K. Awareness during general anaesthesia-incidence, clinical relevance and monitoring. Acta Anaesthesiol Scand Suppl 1997; 111: 313-4.

9 Bogod DG, Orton JK, Yau HM, Ob TE. Detecting awareness during general anaesthetic caesarean section. An evaluation of two methods. Anaesthesia 1990; 45: 279-84.

10 Tunstall ME. Detecting wakefulness during general anaesthesia for caesarean section. Br Med J 1977; 21 : 1321.

11 Hastings RH, Hon ED, Nghiem C, Wahrenbrock EA. Force and torque vary between laryngoscopists and laryngoscope blades. Anesth Analg 1996; 82: 462-8.

12 Viby-Mogensen J, Engbaek J, Eriksson LI, et al. Good clinical research practice (GCRP) in pharmacodynamic studies of neuromuscular blocking agents. Acta Anaesthesiol Scand 1996; 40: 59-74.

13 Leslie K, Sessler DI, Smith WD, et al. Prediction of movement during propofol/nitrous oxide anesthesia. Performance of concentration, electroencephalographic, pupillary, and hemodynamic indicators.

Anesthesiology 1996; 84: 52-63.

14 Kearse LA Jr, Manberg P, DeBros F, Chamoun F, Sinai $V$. Bispectral analysis of the electroencephalogram during induction of anesthesia may predict hemodynamic responses to laryngoscopy and intubation.

Electroencephalogr Clin Neurophysiol 1994; 90 : 194-200.

15 Glass PSA, Shafer SL, Jacobs JR, Reves JG. Intravenous drug delivery systems. In: Miller RD (Ed.). Anesthesia. New York: Churchill Livingstone, 1994: 389-14.

16 Guignard B, Menigaux C, Dupont X, Fletcher D, Chauvin $M$. The effect of remifentanil on the bispectral index change and hemodynamic responses after orotracheal intubation. Anesth Analg 2000; 90: 161-7.

17 Brubn J, Bouillon TW, Shafer SL. Electromyographic activity falsely elevates the bispectral index. Anesthesiology 2000; 92: 1485-7. 